\title{
Sol-gel synthesis of palladium nanoparticles supported on reduced graphene oxide: an active electrocatalyst for hydrogen evolution reaction
}

\author{
FERESHTEH CHEKIN* \\ Young Researchers and Elite Club, Ayatollah Amoli Branch, Islamic Azad University, Amol 678, Iran
}

MS received 30 November 2014; accepted 16 March 2015

\begin{abstract}
In this work, the synthesis and characterization of palladium nanoparticle-reduced graphene oxide hybrid (Pd-rGO) material is reported. Techniques of X-ray diffraction, transmission electron microscope (TEM), energy-dispersive X-ray, FT-IR spectroscopy, thermogravimetric analysis and cyclic voltammetry were used to characterize the structure and properties of the Pd-rGO. Results demonstrate the effect of Pd on the reduced GO. The average particle size of the Pd nanoparticles supported on rGO obtained from TEM is about 12-18 nm. Moreover, glassy carbon electrode (GCE) modified with palladium nanoparticle-graphene oxide hybrid (Pd-rGO/GCE) was prepared by casting of the Pd-rGO solution on GCE. The electrochemical and catalytic activity of the Pd-rGO/GCE was studied in $0.1 \mathrm{M} \mathrm{H}_{2} \mathrm{SO}_{4}$ solution. The Pd-rGO/GCE electrode exhibited remarkable electrocatalytic activity for the hydrogen evolution reaction (HER). At potential more negative than $-0.4 \mathrm{~V}$ vs. $\mathrm{Ag}|\mathrm{AgCl}| \mathrm{KCl}_{3 \mathrm{M}}$, the current is mainly due to hydrogen evolution reaction. Finally, the kinetic parameters of hydrogen evolution reaction are also discussed on the Pd-rGO/GCE.
\end{abstract}

Keywords. Reduced graphene oxide; palladium nanoparticles; hybrid; hydrogen evolution reaction.

\section{Introduction}

Already various applications utilizing graphene-based material have been reported such as transparent electrodes in solar cells, ${ }^{1-3}$ catalytic electrodes in fuel cells, ${ }^{4}$ supercapacitors ${ }^{5,6}$ as well as electrodes in transistors ${ }^{7}$ and sensors. ${ }^{8}$ Due to its low catalytic activity, graphene is often decorated with catalytic nanoparticles or quantum dots for applications in fuel cells or optoelectronics, ${ }^{9}$ respectively, resulting in hybrid material with both advantages of graphene and nanoparticles often inducing novel properties. For example, platinum or titanium dioxide nanoparticles have high specific surface area and catalytic activity; they have been proven for applications in catalysis ${ }^{10,11}$ and for energy conversion. ${ }^{12,13}$ Also, semiconducting CdSe nanocrystals (NCs) with easily tunable optical and electrical properties have been demonstrated successfully for application in hybrid photovoltaic devices. ${ }^{14,15}$

However, the nanoparticles are often synthesized in solution with ligand shells to prevent aggregation; this in turn decreases the effectiveness of catalysis or charge transfer in fuel cells and solar cells. ${ }^{16}$ This general problem can be overcome by using a framework to support the nanoparticles, keeping them separated and avoiding aggregation. Graphene is an excellent framework and support for nanoparticles. ${ }^{17,18}$ Additionally it favours charge transfer processes at the nanoparticle-graphene interface ${ }^{9}$ as well as charge transport processes making them ideal candidates for interlayer or electrode material in electrocatalysis or photovoltaic..$^{19,20}$

\footnotetext{
*Author for correspondence (fchekin@yahoo.com)
}

Taking advantages of the high electrical conductivity, the ultra-high specific area of graphene ${ }^{8}$ and good catalytic or optoelectric properties of nanoparticles, the obtained nanoparticle-graphene hybrid materials have high potential in energy harvesting applications. So far, much effort has been paid to the synthesis and application of graphene-metal nanoparticle hybrid material. Platinum or silver nanoparticle decorated graphene was successfully synthesized and exhibits highly catalytic behaviour towards methanol and ethanol oxidation and oxygen reduction as electrode material in fuel cells. ${ }^{17,18}$ Another example is CdSe NCs decorated graphene with promising properties for applications in photovoltaics. $^{9,21-23}$

The hydrogen evolution reaction (HER) is an electrochemical process that has received wide attention because of its importance in both fundamental and technological electrochemistry such as fuel cell technology. ${ }^{24-27}$ For development of the hydrogen-based fuel cell systems as power sources for emission-free electric vehicles, preparation of an active electrocatalyst is still the main subject. The nature of the electrocatalytic surface plays a decisive role in the kinetics and mechanism of this reaction. Although Pt and Pd present the highest activity for the HER, the high cost of this material is often very prohibitive. The search for new and less expensive alternative material for HER has been a topic of current interest. ${ }^{28-35}$ Deposition of Pt or Pd particles on the less expensive material such as carbon supports reduced the cost of anode materials in the industrial applications.

In the present article, we introduce a simple method towards functionalization of graphene oxide with Pd nanoparticles. 
The obtained Pd-graphene oxide was characterized using transmission electron microscopy (TEM), X-ray diffraction (XRD), energy-dispersive X-ray (EDAX), FT-IR spectroscopy and thermogravimetric analysis (TGA). The HER was studied in sulphuric acid solution on glassy carbon electrode (GCE) modified with Pd-rGO as a low cost electrocatalyst.

\section{Experimental}

\subsection{Materials and apparatus}

Graphite flakes were purchased from Asbury Graphite Mills, Inc. (Asbury, $\mathrm{NJ}$ ). All the reagents like $\mathrm{HCl}$ (AR: 37.5\%), $\mathrm{H}_{2} \mathrm{SO}_{4}$ (AR: $98 \%$ ), $\mathrm{H}_{2} \mathrm{O}_{2}$ (AR: $30 \%$ ) and $\mathrm{H}_{3} \mathrm{PO}_{4}$ (AR: $60 \%$ ) were obtained from Fluka Chemicals (Germany). Potassium permanganate was purchased from Tianjin Jiangtian Chemical Reagent Co. Ltd. in China. Gelatin was obtained from Beijing Aoboxing Universeen Bio-Tech Co. Ltd. (Beijing, China). Palladium nitrate was purchased from Aldrich. All other chemicals were analytical grade and were used as purchased.

Electrochemical measurements were performed with an Autolab Potentiostat/Galvanostat (Netherlands). The threeelectrode system consists of a Pd-rGO/GCE as working electrode, $\mathrm{Ag}|\mathrm{AgCl}| \mathrm{KCl}_{3 \mathrm{M}}$ as the reference electrode and a platinum wire as an auxiliary electrode (Metrohm) were used in all voltammetric experiments. LEO-Libra 120 microscope was employed for Pd-rGO transmission electron microscopy images. Fourier transform infrared spectroscopy studies were carried out with BRUKER FT-IR spectrometer. Hitachi S$3500 \mathrm{~N}$ SEM with electron diffraction and EDAX analysis was used for chemical characterization of a specimen. The crystallization and purity of the synthesized samples were characterized by XRD. The TGA was carried with Mettler Toledo TGA/SDTA 851e.

\subsection{Preparation of $P d-r G O$ hybrid}

Graphene oxide was fabricated based on the modified Hammer's method. ${ }^{36}$ In a typical procedure, about $20 \mathrm{mg}$ of GO was loaded in a $250-\mathrm{ml}$ round bottom flask and $100 \mathrm{ml}$ of distilled water was then added, yielding an inhomogeneous yellowish-brown dispersion. The gelatin was prepared separately by adding $2 \mathrm{~g}$ of gelatin crystal in $100 \mathrm{ml}$ of distilled water using hot plate stirrer for maintaining the temperature of $80^{\circ} \mathrm{C}$ for $30 \mathrm{~min}$ to complete dissolution. After that, the pale yellow coloured gelatin solution was added dropwise to yellowish-brown coloured $\mathrm{GO}$ dispersion at $80^{\circ} \mathrm{C}$ using same hot plate stirrer for complete addition. Briefly, $10 \mathrm{ml}$ palladium nitrate solution ( $1 \mathrm{M}$ ) was added to the above solution with continuous stirring. This mixture was allowed to stir for $20 \mathrm{~h}$ at $95^{\circ} \mathrm{C}$ using hot plate stirrer formed blackish gel. Finally, the resulting blackish gel was mixed with small amount of hot water and centrifuged at $7000 \mathrm{rpm}$ for $30 \mathrm{~min}$ followed by washing with hot water three times to remove excess gelatin and nitrate. The obtained solid product of $\mathrm{Pd}-$ rGO hybrid was redispersed in distilled water $\left(1 \mathrm{mg} \mathrm{ml}^{-1}\right)$ and stored at $4^{\circ} \mathrm{C}$ for further application.

\subsection{Fabrication of $\mathrm{P} d-r G O / G C E$}

The dispersed solution of Pd-rGO hybrid was sonicated for $20 \mathrm{~min}$. Finally, a high dispersed solution was formed. Prior to use, the GCE (diameter $1.8 \mathrm{~mm}$ ) was first polished with alumina $(0.05 \mu \mathrm{m})$ slurry and ultrasonically cleaned with ethanol and double distilled water then dried in room temperature. Briefly, $5 \mu$ of Pd-rGO hybrid solution was coated on the GCE surface and dried in air.

\section{Results and discussion}

Figure 1 displays XRD pattern of the $\mathrm{rGO}$ and $\mathrm{Pd}-\mathrm{rGO}$ hybrid. The Pd-rGO sample shows a broad peak at approximately $2 \theta=11^{\circ}$ corresponding to the (002) reflection of rGO. The Pd loaded on rGO surface nearly has no influence on rGO structure. Pd phase has not been detected in the XRD patterns of Pd-rGO powders, possibly because the Pd content on rGO surface is not enough to form clearly crystalline or Pd is an amorphous phase.

Figure 2 displays TEM image of the rGO and Pd-rGO hybrid catalysts. The TEM image shows the presence of uniform well-dispersed Pd nanoparticles on rGO sheet. From TEM image, we can estimate the average particle sizes of

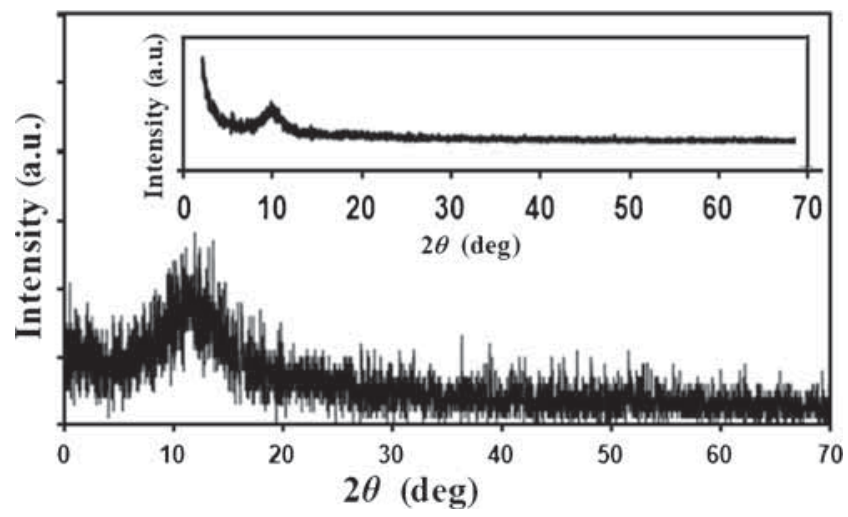

Figure 1. XRD pattern of Pd-rGO hybrid. Inset: XRD pattern of rGO.
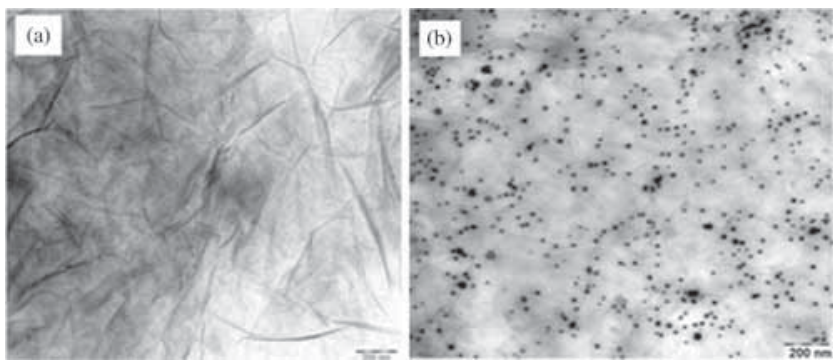

Figure 2. TEM image of (a) rGO and (b) Pd-rGO hybrid. 


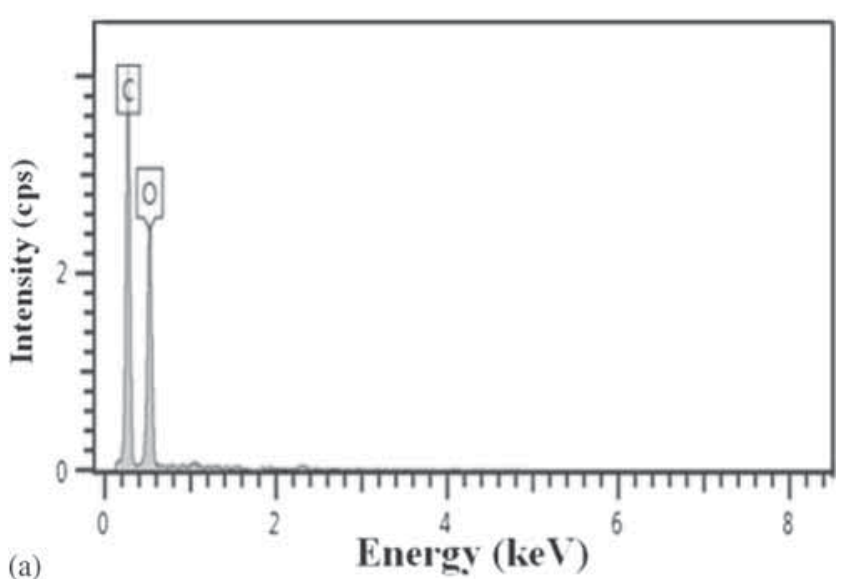

(a)

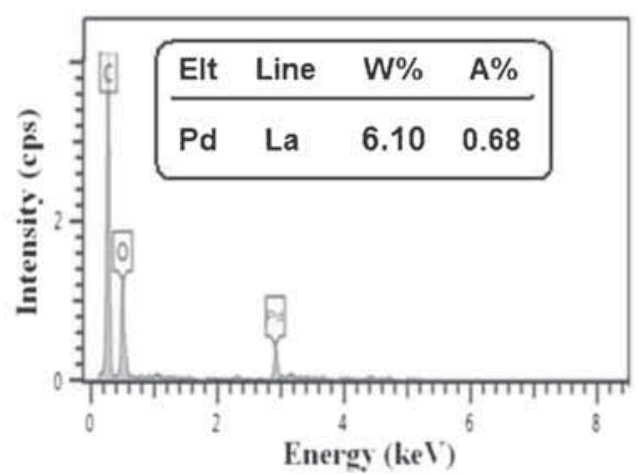

(b)

Figure 3. EDAX pattern of (a) rGO and (b) Pd-rGO hybrid.

the Pd nanoparticles supported on rGO to range $12-18 \mathrm{~nm}$. It also appears that there are some agglomerations of the $\mathrm{Pd}$ nanoparticles on $\mathrm{rGO}$ in the range of $20-35 \mathrm{~nm}$.

EDAX analysis (figure 3) clearly shows the presence of $\mathrm{Pd}$ $(6.1 \%)$ in the sample and that the sample consists mainly of carbon with amount of oxygen probably due to the presence of unreduced oxygen functional groups.

The decoration of the surface of the graphene sheets by palladium nanoparticles was discussed by FT-IR spectroscopy. FT-IR spectrum (figure 4) revealed that the resultant $\mathrm{Pd}-\mathrm{rGO}$ hybrid contained several functional groups like $-\mathrm{OH}\left(3425 \mathrm{~cm}^{-1}\right), \mathrm{C}-\mathrm{O}\left(1075 \mathrm{~cm}^{-1}\right)$ and $\mathrm{C}=\mathrm{O}\left(1630 \mathrm{~cm}^{-1}\right)$. Therefore it has a strong tendency to readily interact with metal ions by hydroxyl and carboxyl group. A peak at $600 \mathrm{~cm}^{-1}$ was signified the formation of $\mathrm{Pd}-\mathrm{O}$ bond. It is well recognized that the $\mathrm{Pd}-\mathrm{rGO}$ bonding can be formed through some physic/chemical interactions such as Vander Waals force, H-bonding and other bonds. Pd atoms may possibly react with the $-\mathrm{OH}$ and $-\mathrm{COOH}$ groups on the functionalized $\mathrm{rGO}$ and thus the bonding $\mathrm{C}-\mathrm{O}-\mathrm{Pd}$ or $\mathrm{O}=\mathrm{C}-\mathrm{O}-\mathrm{Pd}$ might form through a dehydration reaction.

We have examined the thermal stability of the prepared rGO and Pd-rGO a nitrogen atmosphere using TGA. As shown in figure 5, the $\mathrm{Pd}-\mathrm{rGO}$ loses its weight in two steps. The first step is at $100^{\circ} \mathrm{C}$ revealing the evaporation of surface adsorbed water molecules. Second step of weight loss appeared in $200^{\circ} \mathrm{C}$ suggesting the decomposition of labile oxygen $\left(\mathrm{CO}, \mathrm{CO}_{2}, \mathrm{COOH}\right.$ and $\mathrm{H}_{2} \mathrm{O}$ vapours) containing

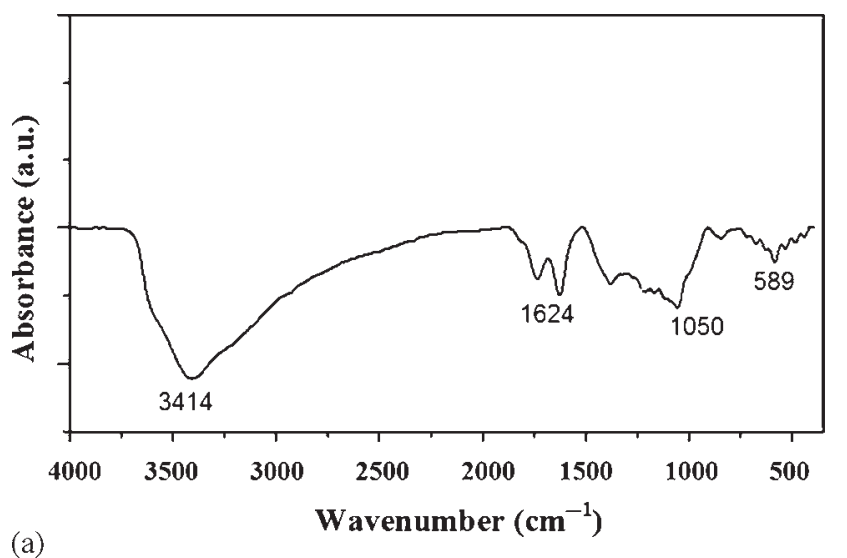

(a)

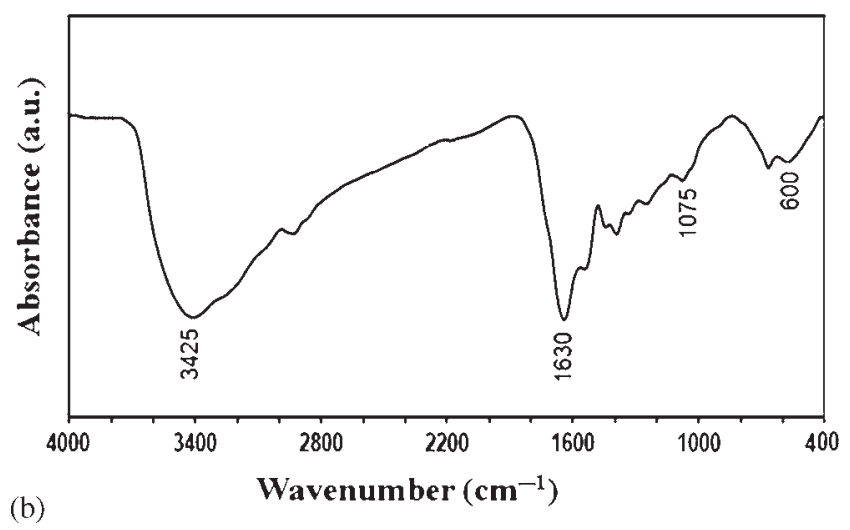

Figure 4. FT-IR spectra of (a) rGO and (b) Pd-rGO hybrid .

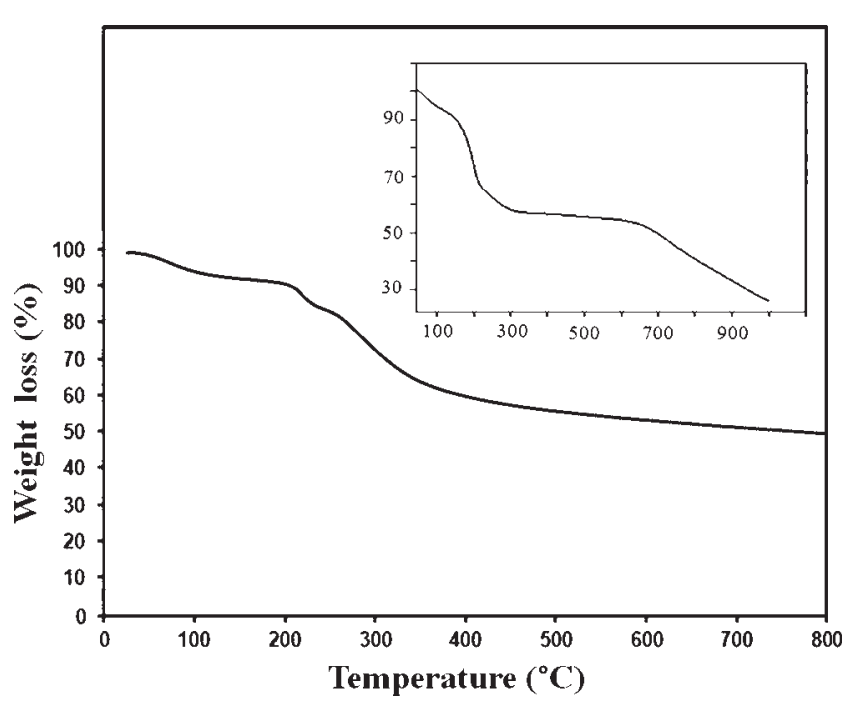

Figure 5. TGA curve of Pd-rGO hybrid. Inset: TGA curve of rGO.

functional groups of rGO. The Pd-rGO catalyst shows high thermal stability. The TGA data also suggest that the presence of $\mathrm{Pd}$ nanoparticles on the reduced graphene sheets increases the thermal stability of the Pd-rGO catalyst. However, the mechanism of increasing the thermal stability of graphene by the $\mathrm{Pd}$ nanoparticles is not clearly explained at this point. A comparison of particle size, temperature and 
Table 1. Compared parameters of synthesized Pd-rGO catalyst with different materials.

\begin{tabular}{lccccc}
\hline Mediator & Method & Agent & $\begin{array}{c}\text { Particle } \\
\text { size }(\mathrm{nm})\end{array}$ & $\begin{array}{c}\text { Synthesized } \\
\text { temperature }\left({ }^{\circ} \mathrm{C}\right)\end{array}$ & Reference \\
\hline $\mathrm{Pd} / \mathrm{Fe}_{3} \mathrm{O}_{4} /$ graphene & Solvothermal & $\mathrm{FeCl}_{3}$ & 25 & 130 & 37 \\
$\mathrm{Pd} / \mathrm{graphene} \mathrm{oxide}^{-}$ & Microwave & $\mathrm{Hydrazin}$ & 14 & 150 & 38 \\
$\mathrm{Pd}-\mathrm{TiO}_{2}$ & Sputtering & - & 23 & 900 & 39 \\
$\mathrm{Pd}-\mathrm{TiO}_{2}$ & Electrospinning & Polyvinyl pyrrolidone & 25 & 600 & 40 \\
$\mathrm{Pd}-\mathrm{TiO}_{2}$ & Sol-gel & - & 30 & 500 & 41 \\
$\mathrm{Pd} / \mathrm{carbon}_{2}$ nanotubes & Chemical & $\mathrm{NaBH}_{4}$ & $5-20$ & 335 & 42 \\
$\mathrm{Au} @ \mathrm{Pd}$ & Chemical & Ascorbic acid & $11-33$ & 90 & 43 \\
$\mathrm{Pd}$ & Chemical & NaBH & 130 & 25 & 44 \\
$\mathrm{Pd}$ & Electrochemical & - & $50-150$ & 25 & 45 \\
$\mathrm{Pd}-\mathrm{rGO}$ & Sol-gel & Gelatin & 15 & 95 & This work \\
\hline
\end{tabular}

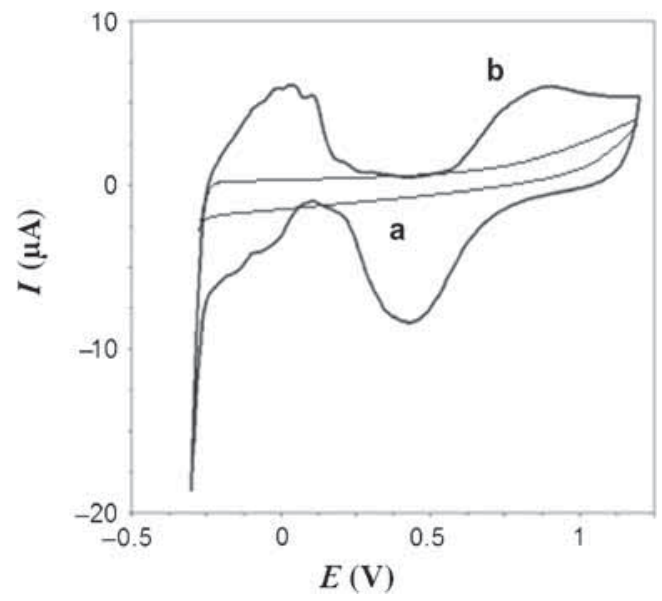

Figure 6. Cyclic voltammogram of (a) $\mathrm{rGO} / \mathrm{GCE}$ and (b) $\mathrm{Pd}-$ $\mathrm{rGO} / \mathrm{GCE}$ in $0.1 \mathrm{M} \mathrm{H}_{2} \mathrm{SO}_{4}$ at a scan rate of $5 \mathrm{mV} \mathrm{s}^{-1}$.

synthesis method of $\mathrm{Pd}-\mathrm{rGO}$ catalyst synthesized in this work with those already reported ${ }^{37-45}$ in literatures is shown in table 1. As shown, parameters are comparable with other results.

To evaluate the electrochemical activity of rGO and $\mathrm{Pd}-$ rGO hybrid, cyclic voltammograms experiments were tested within a potential range from -0.3 to $1.2 \mathrm{~V}$ at a scanning rate of $50 \mathrm{mV} \mathrm{s}^{-1}$ in the solution of $0.1 \mathrm{M} \mathrm{H}_{2} \mathrm{SO}_{4}$. As seen from figure 6 , the $\mathrm{Pd}-\mathrm{rGO}$ film deposited on a GCE was electrochemically active in which hydrogen adsorption characteristics were presented. The electrochemically active surface area (ECSA) was estimated by integrating the voltammograms corresponding to charge of $\mathrm{H}^{+}$adsorption, $Q_{\mathrm{H}}$ $\left(Q_{\mathrm{H}}=0.0125 \mu \mathrm{C}\right)$, from the electrode surface assuming that a monolayer of hydrogen corresponds to an adsorption charge of $210 \mu \mathrm{C} \mathrm{m}^{-2}$ by employing the equation: ${ }^{46,47}$

$$
\begin{aligned}
\text { ECSA } & {\left[\mathrm{m}^{2} \mathrm{~g}^{-1} \text { of } \mathrm{Pd}\right]=Q_{\mathrm{H}}\left[\mu \mathrm{C} \mathrm{m}^{-2}\right] /\left(210\left[\mu \mathrm{C} \mathrm{m}^{-2}\right]\right.} \\
& \left.\times \text { electrode loading }\left[\mathrm{m}^{2} \mathrm{~g}^{-1} \mathrm{Pd}\right]\right) .
\end{aligned}
$$

The ECSA for the Pd-rGO hybrid was estimated to be $11.9 \mathrm{~m}^{2} \mathrm{~g}^{-1} \mathrm{Pd}$, and the high ECSA was because of

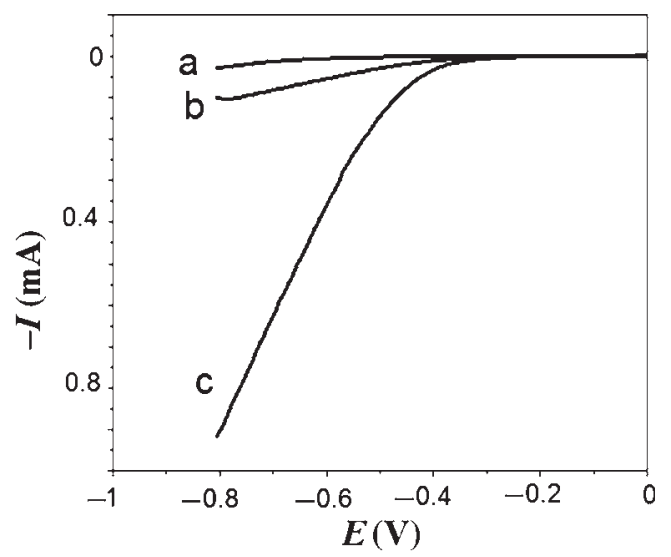

Figure 7. Linear sweep voltammograms of (a) bare GCE, (b) $\mathrm{rGO} / \mathrm{GCE}$ and (c) $\mathrm{Pd}-\mathrm{rGO} / \mathrm{GCE}$ in $0.1 \mathrm{M} \mathrm{H}_{2} \mathrm{SO}_{4}$ at a scan rate of 5 $\mathrm{mV} \mathrm{s}^{-1}$.

high theoretical specific surface area of graphene as a twodimensional (2D) nanomaterial that allows easy deposition of the metal catalyst. This is due to the presence of $2 \mathrm{D}$ flat planes and oxygen-containing groups.

To evaluate the activity of the Pd-rGO catalyst, the electrocatalysis of HER was studied by linear sweep voltammetry, and results are shown in figure 7. As expected, the electrocatalytic activity improves at surface of $\mathrm{Pd}-\mathrm{rGO} / \mathrm{GCE}$ (surface area $=0.057 \mathrm{~cm}^{2}$, curve c) as though the onset potential of HER occurs at about $-0.4 \mathrm{~V} v$ s. $\mathrm{Ag}|\mathrm{AgCl}| \mathrm{KCl}_{3 \mathrm{M}}$ and is indicated by an abrupt increase of the cathodic current. Also, the experiment concerning HER on a bare GCE (surface area $=0.042 \mathrm{~cm}^{2}$, curve a) and GO/GCE (surface area $=0.025 \mathrm{~cm}^{2}$, curve b) electrodes was studied as shown in figure 7. As can be seen, at the same current density, the overpotential of HER at $\mathrm{Pd}-\mathrm{rGO} / \mathrm{GCE}$ is lower than that at GCE and GO/GCE.

The onset potential of HER is about $-0.38 \mathrm{~V}$ for $\mathrm{Pd}-\mathrm{rGO}$ catalyst, which is comparable with $\mathrm{WO}_{3}$ nanorods catalyst $(-0.4 \mathrm{~V}), \mathrm{WO}_{3} / \mathrm{C}$ catalyst $(0 \mathrm{~V}), \mathrm{Ni}$ nanowires catalyst $(-1.1 \mathrm{~V}), \mathrm{Pt} / \mathrm{Al}_{2} \mathrm{O}_{3} / \mathrm{Al}$ catalyst $(-0.35 \mathrm{~V}), \mathrm{Cu} / \mathrm{Pt}$ nanoparticles catalyst $(-0.3)$ and $\mathrm{WO}_{3}$ /carbon nanotube catalyst $(-0.65 \mathrm{~V}) .{ }^{48-53}$ 


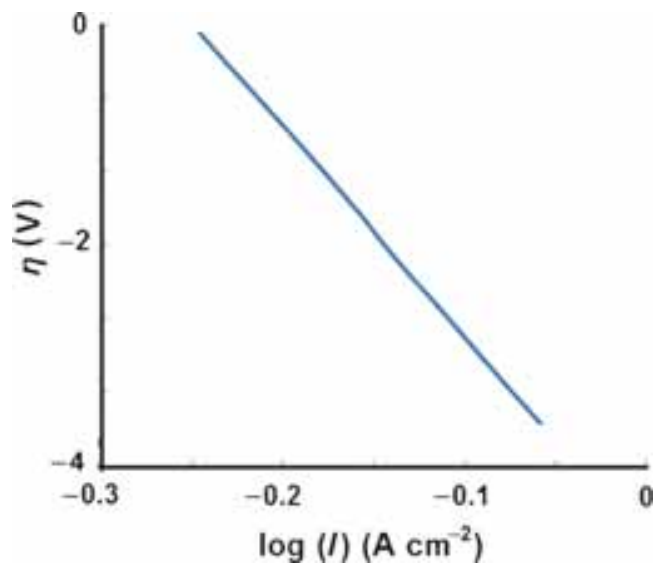

Figure 8. Tafel plot for HER on Pd-rGO/GCE in $0.1 \mathrm{M} \mathrm{H}_{2} \mathrm{SO}_{4}$ by changing the overpotential values and measure the steady state current of chronoamperometric plots.

Tafel plot of Pd-rGO was calculated and transferred from record chronoamperometry plots for a wide potential range by changing the overpotential values and measure the steady state current for each graphs, as shown in figure 8 . The Tafel slope for the Pd-rGO electrocatalysts is $-122 \mathrm{mV} \mathrm{deg}^{-1}$. The HER mechanism at metal (Me) electrode is based on a 2-step reaction that involves an adsorbed $\mathrm{H}$ intermediate, as shown for acidic media below ${ }^{51}$

$$
\begin{aligned}
& \mathrm{H}_{3} \mathrm{O}^{+}+1 \mathrm{e}^{-}+\mathrm{Me} \rightarrow \mathrm{MeH}_{\text {ads }}+\mathrm{H}_{2} \mathrm{O} \text { (Volmer step), } \\
& \begin{aligned}
& \mathrm{MeH}_{\text {ads }}+\mathrm{H}_{3} \mathrm{O}^{+}+1 \mathrm{e}^{-} \rightarrow \mathrm{H}_{2} \uparrow+\mathrm{H}_{2} \mathrm{O} \\
&+\mathrm{Me} \text { (Heyrovsky step), } \\
& 2 \mathrm{MeH}_{\text {ads }} \rightarrow \mathrm{H}_{2} \uparrow+2 \mathrm{Me} \text { (Tafel step). }
\end{aligned}
\end{aligned}
$$

The Tafel equation plays an important role in estimating the kinetic mechanism. The Tafel slope is $b=2.303 R T /(\alpha F)$. The charge-transfer coefficient, $\alpha$, depends on the ratedetermining step (rds) for multi-step reactions. The value of $\alpha$ is 0.5 when the rds is Volmer reaction step; the value of $\alpha$ is 1.5 when the rds is Heyrovsky reaction step; the value of $\alpha$ is 2 when the rds is step Tafel reaction. ${ }^{49}$ In addition, the Tafel slope $b=122 \mathrm{mV} \mathrm{deg}^{-1}$ for HER on Pd-rGO/GCE in this work, $\alpha=1.83$ calculated from $b=2.303 R T /(\alpha F)$. Therefore, Tafel reaction step supposed to be rds for HER on Pd-rGO/GCE.

The Tafel slopes refer to the plots of $\ln i v s$. overpotential $(\eta)$ for HER and the exchange current $\left(i_{0}\right)$ density was derived by extrapolation of the linear part of Tafel plots to zero current potential.

These calculations were made by using the following equation: ${ }^{54}$

$$
\eta=(R T / \alpha n F) \ln i_{0}-(R T / \alpha n F) \ln i,
$$

which is valid at high-overpotential approximation regime. The practical measurement of the electrode activity determinates the overpotential for a constant current density which is $0.60 \mathrm{~mA} \mathrm{~cm}{ }^{-2}$ in our studies, which is higher

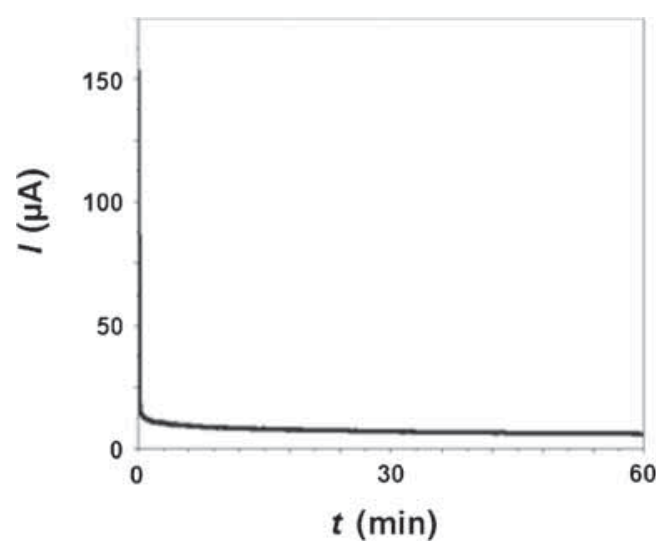

Figure 9. Chronoamperometric curve for Pd-rGO/GCE in $0.1 \mathrm{M}$ $\mathrm{H}_{2} \mathrm{SO}_{4}$ solution at a fixed potential of $-0.5 \mathrm{~V}$.

than for $\mathrm{WO}_{3}$ nanorods $\left(2.75 \times 10^{-3} \mathrm{~mA} \mathrm{~cm}{ }^{-2}\right), \mathrm{WO}_{3}$ black $\left(0.86 \times 10^{-3} \mathrm{~mA} \mathrm{~cm}^{-2}\right), \mathrm{WO}_{3}$ supported on carbon black $\left(52.00 \times 10^{-3} \mathrm{~mA} \mathrm{~cm}^{-2}\right), \mathrm{C} / \mathrm{CoSn}\left(0.20 \mathrm{~mA} \mathrm{~cm}^{-2}\right)$, $\mathrm{C} / \mathrm{CoSnZn}\left(0.70 \mathrm{~mA} \mathrm{~cm}^{-2}\right), \mathrm{C} / \mathrm{CoSnZnePd}\left(1.90 \mathrm{~mA} \mathrm{~cm}^{-2}\right)$, monoclinic $\mathrm{WO}_{3}$ nanoplates $\left(1.61 \mathrm{~mA} \mathrm{~cm}{ }^{-2}\right)$, monoclinic $\mathrm{WO}_{3}$ nanoplates $\left(2.09 \mathrm{~mA} \mathrm{~cm}{ }^{-2}\right)$, Pd-modified carbon fibre $\left(2.70 \times 10^{-3} \mathrm{~mA} \mathrm{~cm}^{-2}\right)$ and Pd-modified nickel-coated carbon fibre $\left(1.20 \mathrm{~mA} \mathrm{~cm}^{-2}\right){ }^{48,49,55-57}$ The high exchange current density of Pd-rGO is implied the lower intrinsic resistance for electronic diffusion in the electrochemical reactions. Throughout from Tafel slope, the number of electron related with hydrogen evolution was also calculated. The number of electrons is 0.76 for Pd-rGO and close to the theoretical number of electrons for HER. Conway and co-workers ${ }^{58}$ have shown, by means of Tafel polarization and impedance measurements on several Pt single crystal electrodes, that at low overpotentials the reaction rate of the HER is controlled by the diffusion of $\mathrm{H}_{2}$ from the surface. At more negative overpotentials, the reaction rate is controlled by the recombination of adsorbed $\mathrm{H}$ atoms on the electrode surface. Thus the slope of $122 \mathrm{mV} \mathrm{deg}^{-1}$ and $\alpha$ of 1.83 , usually determined at wide overpotentials range, Tafel reaction step supposed to be rds for HER on Pd-rGO/GCE.

Finally, the long-term stability of $\mathrm{Pd}-\mathrm{rGO}$ hybrid modified GC electrode for hydrogen evolution was investigated with chronoamperometric curves recorded at $-0.5 \mathrm{~V} v s$. $\mathrm{Ag}|\mathrm{AgCl}| \mathrm{KCl}_{3 \mathrm{M}}$ in $0.1 \mathrm{M} \mathrm{H}_{2} \mathrm{SO}_{4}$. The result (figure 9) indicated the current does not drop significantly even after $1 \mathrm{~h}$. This result showed that Pd-rGO modified GC electrode had good steady state electrolysis activity for hydrogen evolution in an acidic media.

\section{Conclusion}

A new route has been developed to prepare Pd-rGO hybrid nanocatalyst. Results of FT-IR, EDAX, TEM, TGA and cyclic voltammetry demonstrate the effect of Pd on the reduced GO. To investigate the catalytic efficiency of PdrGO hybrid, the hydrogen evolution reaction was studied 
using the deposited film of Pd-rGO hybrid on GCE in $0.1 \mathrm{M} \mathrm{H}_{2} \mathrm{SO}_{4}$ solution using LSV. The electrocatalytic activity improves at the surface of Pd-rGO/GCE as though the onset potential of HER occurs at about $-0.4 \mathrm{~V} v s$. $\mathrm{Ag}|\mathrm{AgCl}| \mathrm{KCl}_{3 \mathrm{M}}$ and is indicated by an abrupt increase of the cathodic current. Pd-rGO hybrid modified GC electrode showed long-term stability for hydrogen evolution in an acidic media.

\section{Acknowledgements}

I gratefully acknowledge the financial support by the Young Researchers and Elite Club, Ayatollah Amoli Branch, Islamic Azad University.

\section{References}

1. Wang Y, Liu J, Liu L and Sun D 2011 Nanoscale Res. Lett. 6 241

2. Wang $\mathrm{H}$ and $\mathrm{Hu}$ Y H 2012 Energy Environ. Sci. 58182

3. Sahoo N G, Pan Y, Li L and Chan S H 2012 Adv. Mater. 24 4203

4. Xin Y, Liu J G, Zhou Y, Liu W, Gao J, Xie Y, Yin Y and Zou Z 2011 J. Power Sources 1961012

5. Luan V H, Tien H N, Hoa L T, Hien N T M, Oh E S, Chung J, Kim E J, Choi W M, Kong B S and Hur S H 2013 J. Mater. Chem. A 1208

6. Li S M, Wang Y S, Yang S Y, Liu C H, Chang K H, Tien H W, Wen N T, Ma C C M and Hu C C 2013 J. Power Sources 225 347

7. Wu Y, Jenkins K A, Valdes-Garcia A, Farmer D B, Zhu Y, Bol A A, Dimitrakopoulos C, Zhu W, Xia F, Avouris P and Lin Y M 2012 Nano Lett. 123062

8. Hill E W, Vijayaragahvan A and Novoselov K 2011 Sens. J. IEEE 113161

9. Lin Y, Zhang K, Chen W, Liu Y, Geng Z, Zeng J, Pan N, Yan L, Wang X and Hou J G 2010 ACS Nano 43033

10. Jin Y, Shen Y and Dong S 2004 J. Phys. Chem. B 1088142

11. Radhakrishnan C, Lo M K F, Warrier M V, Garcia-Garibay M A and Monbouquette H G 2006 Langmuir 225018

12. Plass R, Pelet S, Krueger J and Gratzel M 2002 J. Phys. Chem. B 1067578

13. Blackburn J L, Selmarten D C and Nozik A J 2003 J. Phys. Chem. B 10714154

14. Zhou Y, Eck M, Men C, Rauscher F, Niyamakom P, Yilmaz S, Dumsch I, Allard S, Scherf U and Kruger M 2011 Sol. Energy Mater. Sol. Cells 953227

15. Ren S, Chang L Y, Lim S K, Zhao J, Smith M, Zhao N, Bulović V, Bawendi M and Gradeĉak S 2011 Nano Lett. 113998

16. Ginger D S and Greenham N C 2000 J. Appl. Phys. 871361

17. Shang N, Papakonstantinou P, Wang P and Silva S R P $2010 \mathrm{~J}$. Phys. Chem. C 3715837

18. Qiu J D, Wang G C, Liang R P, Xia X H and Yu H W $2011 \mathrm{~J}$. Phys. Chem. C 3115639

19. Wang Z, Puls C P, Staley N E, Zhang Y, Todd A, Xu J, Howsare C A, Hollander M J, Robinson J A and Liu Y 2011 Physica E 44521
20. Gong F, Wang H and Wang Z S 2011 Phys. Chem. Chem. Phys. 1317676

21. Lu D, Zhang Y, Lin S, Wang L and Wang C 2011 Analyst 136 4447

22. Zedan A F, Sappal S, Moussa S and El-Shall M S 2010 J. Phys. Chem. C 11419920

23. Wang Y, Yao H B, Wang X H and Yu S H 2010 J. Mater. Chem. 21562

24. Trasatti S 1991 Electrochim. Acta 36225

25. Jerkiewicz G and Zolfaghari A 1996 J. Electrochem. Soc. 143 1240

26. Xu Y H, He G R and Wang X L 2003 Int. J. Hydrogen Energy 28961

27. Christmann K 1988 Surf. Sci. Rep. 91

28. Rosalbino F, Delsante S, Borzone G and Angelini E $2007 \mathrm{~J}$. Alloys Compd. 429270

29. Wu Y M, Li W S, Long X M, Wu F H, Chen H Y, Yan J H et al 2005 J. Power Sources 144338

30. Shibli S M A and Dilimon V S 2007 Int. J. Hydrogen Energy 321694

31. Wu M, Shen K P, Wei Z, Song S and Nie M 2007 J. Power Sources 166310

32. Dominguez-Crespo M A, Plata-Torres M, Torres-Huerta A M, Arce-Estrada E M and Hallen-Lópeza J M 2005 Mater. Charact. 5583

33. Jafarian M, Azizi O, Gobal F and Mahjani M G 2007 Int. J. Hydrogen Energy 321686

34. Karimi Shervedani R and Madram A R 2007 Electrochim. Acta $\mathbf{5 3} 426$

35. Xu Y, Chen C, Wang X and Wang Q 2007 Int. J. Hydrogen Energy 32537

36. Hummers W S and Offeman R E 1958 J. Am. Chem. Soc. 80 1339

37. Chandra S, Bag S, Das P, Bhattacharya D and Pramanik P 2012 Chem. Phys. Lett. 51959

38. Siamaki A R, Khder A E R S, Abdelsayed V, Samy El-Shall M and Frank Gupton B 2011 J. Catal. 279163

39. Kim S C, Heo M C and Hahn S H 2005 J. Kor. Phys. Soc. 47 700

40. Moon J, Park Zyung T and Kim D 2010 Sens. Actuators B 149 301

41. Mardare D, Iftimie N, Crişan M, Răileanu M, Yildiz A, Coman T, Pomoni K and Vomvas A 2011 J. Non-Cryst. Solids 357 1774

42. Arrigo R, Wrabetz S, Schuster M E, Wang D, Villa A, Rosenthal D, Girsgdies F, Weinberg G, Prati L, Schlögl R and Su D Sh 2012 Phys. Chem. Chem. Phys. 1410523

43. Song H M, Moosaa B A and Khashab N M 2012 J. Mater. Chem. 2215953

44. Mei Y, Lu Y, Polzer F and Ballauff M 2007 Chem. Mater. 19 1062

45. Diculescu V C, Chiorcea-Paquim A M, Corduneanu O and Oliveira-Brett A M 2007 J. Solid State Electrochem. 11 887

46. Li Y, Gao W, Ci L, Wang Ch and Ajayan P M 2010 Carbon 48 1124

47. Chekin F, Bagheri S and Abd Hamid Sh B 2013 Sens. Actuators $B \mathbf{1 7 7} 898$ 
48. Rajeswari J, Satyananda Kishore P, Viswanathan B and Kanthadai Varadarajan Th 2007 Nanoscale Res. Lett. 2496

49. Zheng H and Mathe M 2011 Int. J. Hydrogen Energy 361960

50. Lee J K, Yi Y, Hye Lee J, Uhm S and Lee J 2009 Catal. Today 146188

51. Habibi B, Pournaghi-Azar M H, Razmi $\mathrm{H}$ and Abdolmohammad-Zadeh H 2008 Int. J. Hydrogen Energy 33 2668

52. Raoof J B, Ojani R, Asghari Esfeden S and Rashid Nadimi S 2010 Int. J. Hydrogen Energy 353937
53. Chekin F, Bagheri S and Abd Hamid Sh B 2013 J. Chin. Chem. Soc. 60447

54. Ojani R, Raoof J B and Hasheminejad E 2013 Int. J. Hydrogen Energy 3892

55. Jin Ham D, Phuruangrat A, Thongtem S and Sung Lee J 2010 Chem. Eng. J. 165365

56. Pierozynski B 2013 Int. J. Hydrogen Energy 387733

57. Döner A, Tezcan F and Kardas G 2013 Int. J. Hydrogen Energy 383881

58. Barber J, Morin S and Conway B E 1998 J. Electroanal. Chem. 446125 